\title{
Research on and Application of the Pattern of Brick Tea in Yangloudong of Xianning City as China National Product of Geographical Indication
}

\author{
Lingli Cai \\ Hubei University of Science and Technology \\ Xianning, Hubei, China 437100
}

\begin{abstract}
The national product of geographical indication, Yangloudong brick tea, is a traditional local specialty of Xianning city, Hubei, where is also one of the birthplace of China "ancient tea-horse road". As tea, its status is little-known in China inland, but it is the "tea of life" in the eyes and hearts of the people of northwest minority. The size of the brick tea is abundantly charming though small but decent. This paper tries to study the historical patterns on the surface of Yangloudong brick tea as a start to reflect the contemporary application of culture of folk pattern on brick tea, aiming at the current brick tea market and put forward the direction of new application of the pattern on brick tea, which can bring profound practical significance to both the protection of the Chinese nation's cultural heritage and the promotion of the whole nation's art.
\end{abstract}

Keywords-brick tea; patterns on brick tea; application of the patterns

\section{INTRODUCTION}

Yangloudong brick tea began in the Jin Dynasty, and became popular and prosperous in Qing Dynasty. Its history is the witness of China's rise and fall in hundred years. Different from the South Road and North Road of " ancient tea-horse road" in Sichuan and Yunnan, it is more like a "brick tea road", which starts from Yangloudong in South of Hubei, along the Yangtze River and passes Hankou, goes eastward from Pingdingshan until arrives in Datong, Shanxi, from which to Zhangjiakou, Hebei, then from Saiyin Mountain, Mongolia to Ulan Bator and finally arrives in the Russian Trade Center kiakhta. The long eight-thousand- mile tea road had been prosperous for more than two centuries. As the tightly pressed black tea, the brick tea is not only a type of goods, more importantly, it carries the great significance of political, economic and cultural exchanges between China inland and the northwest minority.

\section{A BRIEF INTRODUCTION OF THE HISTORY OF BRICK TEA}

In Taihe Period of Tang Dynasty (circa A.D. 827), as drinking tea was popular, tea from Southern Hubei was not only selected as tribute, it also joined in the national trade, thus tea picking was unprecedentedly developed. Then it came to the Jingde Period of Song Dynasty (circa A.D. 1004), the

This article is the research results of the 2016 Youth Project in Humanities and Social Sciences held by education department of Hubei Province (project number is 657). government exchanged the tea in Hunan and Hubei for tea and horse from Inner Mongolia, and set Zhangjiakou as the "exchange market" between Han and Mongolian, which demonstrates that the tea production in southern Hubei was developed to a considerable scale. Until the mid of Ming Dynasty, in order to expand the demand for tea and horse trade, the tea of the entire southern Hubei were transported to Yangloudong for processing, and then shipped to Mongolia and other frontiers. The Southern Hubei has become an important area for tea production in Huguang Area. And Yangloudong has gradually become the production and trade center of tea in Hugaung Area.

In the 35th and 36th year of Emperor Kangxi in Qing Dynasty, after Emperor Kangxi personally occupied Gaerdan, he abolished the tea and horse department and "horse market" set in Ming Dynasty, and opened the trade between Han and Mongolian. ("Dashengkui Historical Material" -information from Inner Mongolia Archives ), therefore, the manufacturing industry of "Maohe Tea" in Yangloudong, which was supplied to the frontiers, was once again prosperous. During Qianlong Period(1751-1760), The two big tea merchants from Shanxi, named "Sanyuchuan" and "Jushengchuan" has come to Yangloudong to buy tea and set factories for pressing tea. Then it came to Daoguang Period (1821 -1850), The foreign firms from Russia, Japan and Germany, etc. and merchants from other provinces such as Tianjin and Guangdong have come to Yangloudong for tea business, thus Yangloudong gradually became the famous tea market within the province. In the last year of Xianfeng Period (1861), due to the improvement of tea production technology, Yangloudong started the mass production of brick tea. But because of the oppression from Russian merchants, the manufacturing industry of national brick green tea, which just emerged and was in preliminary development stage, was on the verge of despair. Then the foreign merchants controlled the brick tea market. They monopolized the tea production and trade. (Rong Hong: Chapter 9 "the 1st Research on Tea Production Area", My Life in China and America") Until from the early period of Republic of China to a few years thereafter, it is the peak period of old tea trade in Yangloudong. After the outbreak of the Anti-Japanese War, tea industry in Yangloudong withered, almost all surrounding tea farms were desolated. After the founding of the PRC, Yangloudong tea industry was recovered 
and developed. And in 2011, it was officially approved as the national geographical indication product.

\section{RESEARCH ON THE PATterns On BRICK TEA}

\section{A. Research on the Traditional Patterns on Brick Tea}

With the continuous development of history, the form of Yangloudong traditional brick has been steadily improved. There have been several very representative forms of brick tea in the history. For example, during the Jingde Period of Song Dynasty, influenced by tea and horse trade, in order to facilitate the transport of tea, the government put forward that the tea should be compressed to a pie-shape after streamed. Thus it is called "slice tea". Then package it in a basket. This is the rudiment of current Yangloudong brick tea. Then it came to the mid of Ming Dynasty, in order to reduce freight and reduce wastage and make it more convenient for long-distance transport, the "pie tea" in Song Dynasty was changed. Treading on the tea and making it into cylindrical shape, called "maohe tea". This is the beginning of the current Yangloudong brick tea. Until the late years of Xianfeng period, tea was formally made into brick-shape, which is similar to the modern shape of brick tea.

For it has been a long time and the history of unrest, as well as the brick tea is not easy to save, now the known earliest extant brick tea was produced in the late years of Qing Dynasty. There is no .real product before this.

But according to historical records, the brick green tea produced by "Sanyuchuan" tea factory during Qianlong Period, was pressed with "Sanyuchuan" brand label, which enjoys high reputation among the Mongolian herdsmen. Due to the large amount of sales of tea, all the tea were pressed with the character "chuan", including tea produced by "Jushengchuan", which is the second strongest tea factory at that time. At that time, the character "chuan", was not only a pattern of a character, but was also as the credibility label of the products, which demonstrates that the brick tea produced in Yangloudong area continued to maintain good-quality compared to the old. With the deepening of imperialist aggression, although these two tea factories were closed, but the brick tea produced in Yangloudong area were still pressed with "chuan" label on the surface.

The surface of the existing Yangloudong brick green tea was pressed with memorial archway, orchid, good-luck knot, and the train, the representative of modern civilization and other kinds of patterns. See Fig.1:

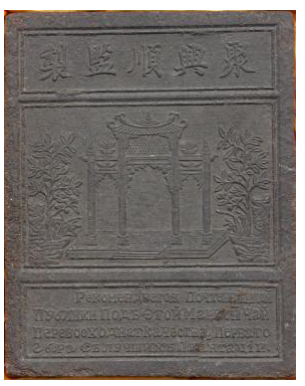

Fig. 1. The brick tea in "memorial archway" brand
Fig.1, the brick tea in "memorial archway" brand was produced in the late years of Qing Dynasty, which is about 1910 according to researches. It is ever known as the world's oldest brick rice tea. After a hundred years, the surface of the brick tea is still clear texture and obvious outline. The top of the front is pressed with traditional character "Juxingshun Jianzhi", and the bottom is with the Russian product introduction, and the middle is respectively pressed with patterns of the grand and profound memorial archway as well as noble and elegant orchid. The "memorial archway" pattern is used as brand label, which is the earliest meaning sign in the history. And the back is pressed with the Buddhist eightcharacter knot of good luck and happiness which can represent that the 16- lattice rectangular brick green tea is produced by Jin merchants. However, at that time, the Russian factories designed their own character patterns, which are different in different tea factory. There is no representative pattern. (Picture is provided by Hubei Zhaoliqiao Brick Tea Factory)

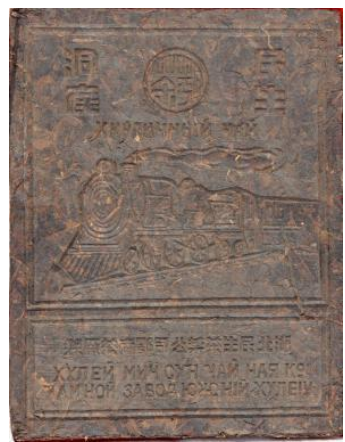

Fig. 2. The "locomotive" brick rice tea

Fig.2, the "locomotive" brick rice tea was produced by China's Minsheng tea company in 1946. Its top was pressed with the "locomotive" pattern. The Russian Huadaosheng Bank abandoned the locomotive with a steam engine to Yangloudong. The steam engine part was adapted for steaming tea and baked tea. The power equipment part of the locomotive was modified for pressing brick tea. The use of the steam engine, greatly improved the productivity of tea. The locomotive pattern was designed by the Russian merchant to commemorate this historic industrial revolution of brick tea. Thus "locomotive" trademark is from this, which becomes the first documentary logo. The train pattern on the surface of brick tea is with clear outline and is extremely exquisite and the title as well as introduction is simple and easy to remember. (Picture is provided by Professor Ding Guangping, Southern Hubei Cultural Center in Hubei) 


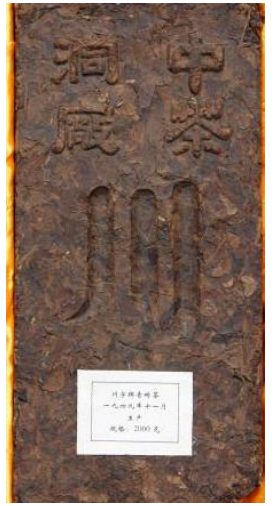

Fig. 3. The "chuan" brand brick tea

Fig.3, the "chuan" brand brick tea was produced after the liberation (in November 1949), by the "China Tea Industrial Company Yangloudong Brick Tea Factory", which is simplified as "China Tea Dong Factory" in traditional Chinese characters, and was the merger of the five Yangloudong tea factories, like "Fuxing", "Juxingshun", "Yixing", "Tianyuanmao", etc. The "chuan" logo originated from the Qianlong period, which can be counted as the earliest design of tea logo for brick tea. At that time, there were three springs in Yangloudong area, Guanyin Spring, Shiren Spring and Liangyin Spring, which were through the town. And at that time, there were many tea factories locating here, with the "Sanyuchuan" and "Jushengchuan" as the top factories. In order to hint the meaning of water bringing wealth and prosperous business, the "chuan" character was pressed on the brick tea. In 1993, the "chuan" brand brick tea was awarded the "China Time-Honored Brand". (Picture is provided by Hubei Zhaoliqiao Brick Tea Factory)

As a traditional labels, the above three kinds of brick tea patterns have been used to date. The sources of patterns are different. Some are borrowed or metaphors, some are documentary, or just a design approach. They not only retain the traditional, but is also the application of brand effect. In addition, as the traditional brick tea, its surface is mainly with characters, for the purpose of introducing brick tea, which often occupy a large part of the surface of brick tea. The drawing is a subsidiary part, whose significance is mainly as brand logo for brick tea. The drawing is placed in the center. Thus, the application and expression of traditional patterns on the brick tea are not mature. It lacks of certain decorative significance.

\section{B. The Study on the Patterns on Modern Brick Tea}

The patterns on modern Yangloudong brick tea are both rich in contents and forms. It also presents profound artistic characteristics. According to different shapes, the brick tea can be divided into square brick tea and circular brick tea, brick tea, some oval brick tea. According to the different patterns, it can be divided into animal type, plant type, character type, scenery type, etc. These patterns mean good luck, conveying a variety of good wishes. However, as the surface area of brick tea is limited, the expression of the decorative pattern is limited. This requires designers pay more attention to the innovation and layout of patterns, which can endow brick tea with unique artistic charm and vitality.

According to the market survey and the production information provided by manufacturers in Yangloudong area, classifying the patterns existing in the brick tea market into the following types,

1) Pattern of character: Brick tea surface is often dominated by single-body words and multi-body words. The common single-body words include "Fu", "Shou" and "Xi", etc. Besides "Caiyuanguangjin" and "Shengyixinglong", the multi-body words include poems and songs, as well as "Baifu Tu" and "Baishou Tu", etc., which cover the entire surface. As the character patterns can express profound meanings and its content is simple and intuitive, it is the most easily accepted by the people. Thus it is the most common pattern among all the patterns on brick tea.

2) Pattern of animal: The main pattern on surface of brick tea is animal. The common patterns are "dragon and phoenix" and "Fish diving", etc. Apply the design methods of symbol, simplization, homophon and other techniques, to express meanings of honor and auspicious, etc. The animal pattern on brick tea has been existing in the traditional sense of the Chinese nation.

3) Pattern of palnt: The common plant patterns of brick tea include to pine, which represents "tlong lifespan" and "guests coming ceaselessly", Peony, which represents "luck and wealth" and "thriving and prosperity" as well as bamboo, which represents "safety" and "confidence", etc. These plants have long been given a new life. As a part of the Chinese folk, it is used to express people's good wishes for life.

4) Pattern of figure: The figures on the surface of brick tea are often the themes of Shakya Muni Buddha, Buddism godness Guanyin, to express the pursuit of religious faith and praying for good luck and happiness.

5) Pattern of landscape: The brick tea with landscape patterns is often pressed with the famous spots. The brick tea with Three Kingdoms Chibi ancient battlefield site is common, which is applied with realistic skills, and with commemorative significance.

In addition to the above classification of brick tea based on different patterns, it can also be classified according to different functions. It can be divided into gift type, goods type and commemorative type. Through the comparison of the real products, it is not difficult to find out that the common artistic features of decorative patterns on brick tea surface are as follow. Firstly, the layout is delicate. The pattern is consistent with the form of brick tea, round or square. And the pattern fully fills the surface, no empty space. In limited space of brick tea surface, create unlimited decorative charm. Secondly, it pays attention to the primary and the subsidiary. It reasonable arranges the proportion, location of the main drawing and auxiliary drawing, thus, it is rich in level and has a strong sense of space. Finally, the number of the objects is accurate. According to the composition of the pattern on the brick tea surface, the number of objects is accurate. Each object does not occupy more space and waste space as it should. 
Among the expression skills, the most widely used is realism. Based on the reality, it shows different images or themes, which represent different meanings. To consumers such a simple and intuitive expression is vivid and easy to understand, which boost purchase.

\section{RESEARCH ON THE APPLICATION OF MODERN PATTERNS ON BRICK TEA}

\section{A. Advocate the Application of Commemorative Patterns on Brick Tea}

It is a new trend to give brick tea as gifts for memorializing a person, memorializing an event, and memorializing a date. For example, customizing a brick tea for birth, marriage and birthday is quite memorable, which is popular among consumers. Thus the pattern on the modern tea packaging not only retains the tradition, but also gradually becomes the ones for gift packaging, which is delicate and exquisite. It becomes an important media for people to deliver affection and respect. Thus it maintains human's relationships.

\section{B. Advocate the Application of Decorative Patterns on Brick Tea}

Chinese long history of culture has created the spirit of Chinese art. The application of the folk patterns, such as bronze ware, lacquer ware, and brocade pattern, etc. forms the brick tea a unique style in terms of aesthetic consciousness, which is natural, friendly, simple, healthy and environmental.

\section{CONCLUSION}

Although Yangloudong Tea is only a small microcosm of China culture, but it embodies the hereditary folk charm of Chinese nation, concentrates the popular beliefs and legends in the era, thus it is a wonderful quintessence of Chinese culture. The purpose of the study on the patterns on surface of Yangloudong brick tea, is to blend the cultural essence of the national patterns in ancient China into the modern design of brick tea surface. The modern design can refer to and apply to the old patterns, while endowing the brick tea with new artistic spirit, so that it is no longer a boring goods, so as to enhance the brand effect of Yangloudong brick tea, and to boost the Yangloudong brick tea, one of the treasures of the Chinese nation, towards a higher and broader market.

\section{REFERENCES}

[1] Local Annals Compilation Committee, Hubei Provicne "Qipu Annals", Chapter 6, Local Specialty I Tea before Foundation of PRC. Haitian Press, July, 1995, 1st edition

[2] "Dashengkui Historical Material", information from Inner Mongolia Archives

[3] Wan Xianchu and Zong Songshan, "Tea Culture in Southern Hubei"Guangxi People's Press, July, 1993

[4] Hu Sibin, "China Brick Green Tea" Hubei Science and Technology Press, November, 2015, 1st edition

[5] Feng Xiaoguang, "The Source of the Ten-thousand-mile Tea Route Decrypt the Yangloudong" Huazhong Normal University Press, October 2015,1 st edition
[6] Mu Fasong, "Economics and Society in Middle Reaches of Yangtze River in Qing Dynasty" Wuhan University, July, 1993, 1st edition

[7] The Republic of China, "Puqi Village Annals"12th Year of The Republic of China, relief printing edition

[8] Tongzhi Chapter 4 "Products" of "Chongyang County Annals"

[9] "Dashengkui Historical Material", information from Inner Mongolia Archives

[10] Local Annals Compilation Committee, Puqi City, Hubei Provicne, "Puqi Annals", Chapter 9 Industry I Tea Industry. Haitian Press, July, 1995, 1st edition.

[11] Local Annals Compilation Committee, Hubei Provicne,"Hubei Province Annals Trade" P348, Hubei People's Press, November, 1992, 1st edition

[12] Trade edition department of Hubei Province Annals, "Selected Historical Materials of Hubei Modern Economic and Trade" (1st series), Tea Trade, 1 st edition in 1984

[13] Shi Nianshu:" The Documentary of the Revitalization of Tea Industry across China in Late of Qing Dynasty and Early of The Republic of China", "Agricultural Archaeology", 2nd phase of 1991, "Tea Culture Issue"

[14] Department of Agricultural Economics, College of Agriculture, Jinling University "Manufacturing and Transport of Yangloudong Old Green Tea in Hubei”, Jinling University, Research in October, 1934, Pressed in 1936. 